\title{
Civic Participation and Self-rated Health: A Cross-national Multi-level Analysis Using the World Value Survey
}

\author{
Saerom Kim ', Chang-yup Kim ', Myung Soon You² \\ ${ }^{1}$ Department of Preventive Medicine, Graduate School of Public Health, Seoul National University, Seoul; ${ }^{2}$ Graduate School of Public Health, Seoul \\ National University, Seoul, Korea
}

Objectives: Civic participation, that which directly influences important decisions in our personal lives, is considered necessary for developing a society. We hypothesized that civic participation might be related to self-rated health status.

Methods: We constructed a multi-level analysis using data from the World Value Survey (44 countries, $\mathrm{n}=50859$ ).

Results: People who participated in voting and voluntary social activities tended to report better subjective health than those who did not vote or participate in social activities, after controlling for socio-demographic factors at the individual level. A negative association with unconventional political activity and subjective health was found, but this effect disappeared in a subset analysis of only the 18 Organization for Economic Cooperation and Development (OECD) countries. Moreover, social participation and unconventional political participation had a statistically significant contextual association with subjective health status, but this relationship was not consistent throughout the analysis. In the analysis of the 44 countries, social participation was of borderline significance, while in the subset analysis of the OECD countries unconventional political participation was a stronger contextual determinant of subjective health. The democratic index was a significant factor in determining self-rated health in both analyses, while public health expenditure was a significant factor in analysis of 18 countries.

Conclusions: Our investigation suggests that civic participation, including unconventional political activity at the contextual level, might be a significant determinant of health status of a country.

Key words: Participation, Self-rated health, Multilevel analysis, World Value Survey

\section{INTRODUCTION}

Civic participation, when people directly influence the outcomes of important decisions in their own lives, is believed to make a happier and more desirable society [1]. Even though civic

Received: July 4, 2014 Accepted: November 24, 2014

Corresponding author: Myung Soon You, PhD

1 Gwanak-ro, Gwanak-gu, Seoul 151-742, Korea

Tel: +82-2-880-2774, Fax: +82-2-762-9105

E-mail: msyou@snu.ac.kr

This is an Open Access article distributed under the terms of the Creative Commons Attribution Non-Commercial License (http://creativecommons.org/licenses/by$\mathrm{nc} / 3.0 /$ ) which permits unrestricted non-commercial use, distribution, and reproduction in any medium, provided the original work is properly cited. participation is pursued in democratic society, it is reasonable to think that more participation may improve the quality of decision-making, reduce social conflict, and reduce expenses related with participation. Previous studies, which explored the relationship between democratic institutions and health, considered civic participation an underlying mechanism for the achievement of a good health status within a country. Several explanations have been used to describe the lengthy path between democratic institutions and health. For example, having a greater political voice that influences a politician's responsiveness to the citizen's needs and concerns eventually results in the state allocating more resources in favor of these public policies [2-4].

In this paper, we aimed to examine the effect of civic participation on health. We joined any political participation (en- 
gagement in various political activities) and social participation (participation in various social activities) into the category of civic participation. In addition, we categorized voting as conventional political participation. Other various forms of political participation were defined as non-conventional political participation.

Previous studies, which examined the relationship between civic participation and health, generally did not treat participation as a salient concept. Instead, they focused on the concept of social capital. Robert Putnam defined social capital as features of a social organization such as trust, norms, and networks that can improve the efficiency of a society by facilitating coordinated actions [5]; many studies measured civic participation as a central feature of social capital. Poortinga [6] used data from 22 countries that participated in the European Social Survey and found that civic participation was strongly associated with self-rated health (SRH). People with higher levels of civic participation were more likely to report good or very good health than people with a lower level of civic participation were. Similarly, another study using data from the World Value Survey (WVS) showed a strong association of social participation with SRH [7]. However, the effects of social capital and social participation were only significant at the individual level, whereas the contextual level of the effect was conflicting.

Another restriction of previous studies that have attempted to measure participation was that they tended to focus on certain types of participation in people's social life. Research focusing on participation within the stream of social capital has conventionally focused on people's engagement in social life, such as their voluntary associations, neglecting their engagement in the political domain [8-10]. In response to these limitations, Szreter and Woolcock [11] called for more attention to political participation that joined the concept of social capital and was defined as norms of respect and a network of trusting relationships between people who interact across explicit, formal, or institutionalized power or authority gradients in society. This concept emphasizes the importance of state-society relations. After the idea of linking social capital as a determinant of health was introduced, political participation such as engaging in local elections was measured to explore the level of social capital linkage and its effect on health [11,12]. A longitudinal study in England revealed that political participation and political efficacy in the community were associated with SRH at a neighborhood level [13], while Lofors and Sundquist
[14] found a strong negative association between social capital linkage and hospitalizations due to depression and/or psychosis. Moreover, Sundquist et al. [15] conducted a cohort study on 2.8 million people in Sweden and found that voting in the local governmental election was associated with coronary heart diseases after adjusting for various individual-level factors, with statistically significant effects at both the individual and neighborhood levels. Studies which investigated effect of political capacity on health according to welfare regime also have revealed social capital and working-class power in social democratic countries has significant positive influence even compared among wealthy democratic countries [16,17].

We aimed to investigate the effect of civic participation on $\mathrm{SRH}$. Civic participation was the main independent variable because it combines the social and political dimensions. Moreover, we aimed to include non-conventional political participation as another main independent variable because nonconventional political participation has been rarely explored and might be reflective of active civic engagement and any difficulties being encountered when having to make important decisions about personal lives and/or surroundings. In addition, we aimed to examine the role of political participation as a collective resource for health. We utilized data from 44 countries that participated in the WVS, adopting multi-level analyses to examine both the compositional and contextual effects of civic participation.

\section{METHODS}

\section{Data and Variables}

The WVS was a major source of data for retrieving the level of social and political participation for each individual and country. These data consist of cross-national survey results from at least 1000 people from each country, collecting each participant's values, beliefs, and attitudes during each era since its first survey was conducted in 1981. To examine the effect of civic participation, these datasets were a valuable resource because they included data on many forms of civic participation, especially data on non-conventional political participation that were added in the fifth wave (2005-2008). In addition, the WVS was used by several previous studies that investigated the relationship between subjective health status and other relevant variables such as social capital, trust, and participation $[7,18,19]$.

The most recently released data from wave 5 (2005-2008) 
[20] were used in our analysis, and we excluded any countries missing data for any major variables. A total of 57 countries were surveyed, but only 44 countries contained the necessary civic participation variables, thus only those 44 countries were included in the analysis (44 countries and year of survey included in the analysis were Argentina [2006], Australia* [2005], Brazil [2006], Bulgaria [2006], Burkina Faso [2007], Canada* [2006], Colombia [2005], Cyprus [2006], Chile* [2006], Egypt [2008], Ethiopia [2007], Finland* [2005], France* [2006], Georgia [2008], Germany* [2006], Ghana [2007], Great Britain* [2006], India [2006], Indonesia [2006], Italy* [2005], Japan* [2005], Malaysia [2006], Mali [2007], Mexico* [2005], Moldova [2006], Morocco [2007], Netherlands* [2006], Norway* [2007], Peru [2006], Poland [2005], Romania [2005], Russian Federation [2006], Serbia [2006], Slovania* [2005], South Africa [2007], South Korea* [2005], Sweden* [2006], Switzerland* [2007], Taiwan [2006], Thailand [2007], Trinidad and Tobago [2006], Turkey* [2007], Ukraine [2006], United States* [2006], Viet Nam [2006], Zambia [2007]. OECD countries are marked with asterisk).

Each country's gross national income per capita (GNIpc) was adapted from the World Bank database [21], and total and public health expenditures were adapted from the World Health Organization Global Health Expenditures database [22]. Moreover, the democracy index was adopted from the "Freedom in the world" report published by Freedom House, which measures political rights and civic liberties according to 25 indicators [23].

\section{Dependent Variable}

The outcome variable was SRH. SRH was assessed by a question in the WVS that asked participants to describe their state of health as excellent, very good, good, fair, poor, or unsure. $\mathrm{SRH}$ has been commonly used in studies as a subjective measure of health and has been validated as a reliable surrogate for general health status $[24,25]$. We stratified SRH into a binary variable as either good or poor.

\section{Independent Variables}

Two major dimensions of civic participation, political participation and social participation, were included as major independent variables. Political participation included two dimensions: conventional and non-conventional participation. Conventional participation was measured as a binary variable by asking whether the respondent had voted on the last parliamentary election. Non-conventional participation measured the participant's involvement in various political activities such as signing a petition, joining a boycott, or attending a lawful, peaceful demonstration. The possible answers to each question were "would never do, might do, and have done" and were scored as zero, one, or two, respectively. We added up the three scores for the overall score, and then rescored each individual score from one to three, with one as the lowest political participation and three as the highest.

Social participation, was measured according to eight categories of organizations with voluntary participation (church/ charity groups; sports/recreational groups; art, music, or educational groups; labor unions; political organizations; environmental organizations; and professional associations). Participants were asked to answer whether or not they are a member, an inactive member, or an active member for each of the eight categories above. We summed the scores for all eight questions, and then rescored each participant's score from one to three, with one as low participation in social activities, two as average participation, and three as high participation. This method of categorizing participation into low, middle, and high participation was also applied in previous studies that have investigated social participation using the WVS data [7].

To explore the effect of civic participation at both the individual and contextual level, we formulated country-level civic participation variables by aggregating all of the participation variables, using the mean value for each country as the aggregated variable.

\section{Controlled Variables}

Individual level variables that are known to be determinants of health such as age, sex, marital status, education, and income were controlled for in the statistical models. At the country level, several variables that we considered to be related to health were included in the model. First, the economic wealth of each country was included in our analysis because it is considered a major determinant of the health status of most countries [26-28]. The GNIpc for all of the included countries was divided by 1000 to standardize this value for comparisons. Second, health spending defined as the percentage of the total gross domestic product spent on health expenditures was also added in the models because it is considered a significant explanatory variable for health outcomes in previous studies $[29,30]$. Although the relationship between health care expenditures and health outcomes is conflicting according to how health outcomes are defined, we decided to include health care expenditure in the models because we thought it might 
be a mediating variable between civic participation and health. Third, the democracy index and share of public health expenditure were added as mediators in the final model. These two variables were considered covariates that bridge civic participation with health status. One previous study has shown that a more democratic country tends to have a lower maternal mortality, lower mortality for those younger than five years, and higher life expectancy than less democratic countries do, after controlling for other factors such as economic status, history of colonization, and educational status [2]. The degree of political freedom within a country, as measured by the democracy index, has also proven to be a significant factor. Franco et al. [31] used the freedom index to measure the level of democracy within a country and found that the freedom index was significantly associated with life expectancy, infant mortality, and maternal mortality in a cross-national regression study of more than 150 countries. The effect of public spending on health is also evident. Mackintosh and Koivusalo [32] found a statistically significant association between public spending on health and health-adjusted life expectancy, whereas Houweling et al. [33] showed that countries with a higher public spending on health had lower inequities between their mortality rates among those younger than five years and the country's economic status, which can result in other improvements to a country's health status.

\section{Statistical Methods}

Pearson correlations and multi-level logistic regression analyses using a hierarchical generalized linear model were used to explore the effects of civic participation. By using multi-level modeling, we were able to distinguish between compositional effects due to individual variables (level one) and the contextual effects due to country variables (level two) on health.

Five models were used for our analysis. Model 1 was an intercept-only model to calculate the intra-class correlation coefficient and to confirm the appropriateness of the multi-level analysis, which indicates whether homogeneity exists between countries. Model 2 was a compositional effect model that included individual variables only. Model 3 included model 2 and country-level civic participation variables were added, but contextual covariates were not included. Model 4 contained all of model 3 , the contextual variables of economic status, and the percentage of total health expenditure for each country. The final model, model 5 , included model 4 , the democracy index, and the percentage of public health expendi-
Table 1. Comparison between those with good and poor self-rated health across demographic characteristics

\begin{tabular}{|c|c|c|c|}
\hline & $\begin{array}{c}n(\%) \\
\text { (total } 50859)\end{array}$ & $\begin{array}{c}\text { Good } \\
\text { health }(\%)\end{array}$ & $\begin{array}{c}\text { OR } \\
(95 \% \text { CI })\end{array}$ \\
\hline \multicolumn{4}{|l|}{ Sex } \\
\hline Male & 24655 (48.48) & 28.72 & 1.00 \\
\hline Female & 26204 (51.52) & 33.5 & $1.25(1.20,1.30)^{* * *}$ \\
\hline \multicolumn{4}{|l|}{ Age (y) } \\
\hline $15-24$ & $8179(15.71)$ & 18.05 & 1.00 \\
\hline $25-34$ & 11682 (22.44) & 21.4 & $1.24(1.15,1.33)^{* * *}$ \\
\hline $35-44$ & 10823 (20.79) & 25.63 & $1.57(1.46,1.68)^{* * *}$ \\
\hline $45-54$ & 8943 (17.18) & 36.41 & $2.60(2.42,2.79)^{* * *}$ \\
\hline $55-64$ & $6444(12.38)$ & 45.05 & $3.72(3.46,4.01)^{* * *}$ \\
\hline$\geq 65$ & $5997(11.52)$ & 55.49 & $5.66(5.25,6.11)^{* * *}$ \\
\hline \multicolumn{4}{|l|}{ Marital status } \\
\hline Cohabitating & 32251 (63.41) & 31.84 & 1.00 \\
\hline $\begin{array}{l}\text { Divorced/separated/ } \\
\text { widowed }\end{array}$ & $6215(12.22)$ & 47.69 & $1.94(1.85,2.06)^{* * *}$ \\
\hline Single & $12393(24.37)$ & 21.25 & $0.58(0.55,0.61)^{* * *}$ \\
\hline \multicolumn{4}{|l|}{ Education ${ }^{1}$} \\
\hline Low & 17358 (34.13) & 42 & 1.00 \\
\hline Middle & 22293 (43.83) & 28.57 & $0.55(0.53,0.58)^{* * *}$ \\
\hline High & 11208 (22.04) & 21.49 & $0.38(0.36,0.40)^{* * *}$ \\
\hline \multicolumn{4}{|l|}{ Income ${ }^{2}$} \\
\hline 1 & 17306 (34.03) & 43.09 & 1.00 \\
\hline 2 & 15481 (30.44) & 30.81 & $0.59(0.56,0.61)^{* * *}$ \\
\hline 3 & 6296 (12.38) & 24.19 & $0.42(0.39,0.44)^{* * *}$ \\
\hline 4 & 11776 (23.15) & 19.68 & $0.32(0.31,0.34)^{* * *}$ \\
\hline \multicolumn{4}{|l|}{ Voter } \\
\hline Yes & 35831 (68.82) & 31.65 & $1.09(1.04,1.14)^{* * *}$ \\
\hline No & 16237 (31.18) & 29.81 & 1.00 \\
\hline \multicolumn{4}{|l|}{ Political activity } \\
\hline 1 (lowest) & 17465 (34.34) & 36.71 & 1.00 \\
\hline 2 (middle) & 21799 (42.86) & 30.71 & $0.76(0.73,0.80)^{* * *}$ \\
\hline 3 (high) & 11595 (22.80) & 25.55 & $0.59(0.56,0.62)^{* * *}$ \\
\hline \multicolumn{4}{|l|}{ Social participation } \\
\hline 1 (lowest) & 19734 (39305) & 37.14 & 1.00 \\
\hline 2 (middle) & 14111 (27.92) & 31.45 & $0.77(0.74,0.81)^{* * *}$ \\
\hline 3 (high) & 16692 (33.03) & 23.62 & $0.52(0.50,0.55)^{* * *}$ \\
\hline
\end{tabular}

$\mathrm{Cl}$, confidence interval; $\mathrm{OR}$, odds ratio.

'Level of education was measured by using 1-9 scale. Here we reorganized the variable into 3 categories. Lowest group indicate education level lower than primary school, high for those attaining higher than completing secondary/university preparing level, and middle for those between.

${ }^{2}$ Income level was measured by using self-rated income level in 1-10 scale. Here we merged the variable into 4 ordinal scale using original scale 1-3 into 1, 4-6 into 2, 7-8 into 3, and 9-10 into 4.

${ }^{* * *} p<0.001$.

tures. Moreover, a subgroup analysis investigating the relationship of civic participation with variables representing po- 
litical and economic settings was constructed for the 18 Organization for Economic Cooperation and Development (OECD) countries included in our analysis.

\section{RESULTS}

Individual level characteristics of the total sample of 50859 participants are shown in Table 1. According to the univariate analysis, those with a poor SRH tended to be female, older, less educated, and have less income than those with a good SRH did. In addition, those who participated in social organizations and were politically active tended to have better SRH; however, those who reported to have voted in the last election tended to have worse SRH in the model not controlled for the individual variables.

The correlation coefficient between each contextual variable is shown in Table 2. Political activity, social participation, GNIpc, and total health expenditure were negatively correlated with fair to poor SRH. It should be noted that a high correlation coefficient of the freedom index is reversed in scale, meaning that the higher the index the more restricted the freedom of the state.

Table 3 gives the results of the multi-level analysis of the 44 countries from the WVS. According to model 1, the intra-class correlation coefficient was $35.44 \%$. Model 2, which analyzed the effect of individual variables after considering the intraclass correlation, found that individuals who voted and participated in social organizations tended to report better SRH, and those who were politically active reported poorer SRH.

The contextual variables were included in the analysis in model 3. Countries with high political activity and social par- ticipation tended to have better SRH. Model 4 included two additional country-level variables, and only the GNIpc was a significant factor. In addition, controlling for contextual confounders attenuated the effect of political activity, whereas social participation became more robust.

In model 5, which included the country-level covariates democracy index and the percentage of public health expenditures, only the democracy index was a significant factor. The more democratic the country (the more freedom the country has, the smaller the index of democracy, which is applied by the Freedom House democracy index) the better the SRH.

The fitness of the model was checked using the log-likelihood ratio. The log-likelihood ratio increased with the addition of more variables. For example, the ratio greatly increased from the transition between model 4 to 5 , and this transition was greater than that between models 3 to 4 . This difference suggests that the democracy index and percentage of public health expenditure were relevant variables in explaining differences in SRH.

Because the effect and influence of political and social participation may differ by country, especially considering the various economic and political statuses of these countries, a subset analysis of the 18 OECD countries included in our analysis was done (Table 4).

Individual level variables demonstrated a similar pattern to the aforementioned results, but being divorced or widowed was no longer negatively associated with SRH among the OECD countries. For the sociopolitical participation variables, those who voted or participated in voluntary social associations tended to have better $\mathrm{SRH}$, and these variables were negatively associated with political activity and were no lon-

Table 2. Pearson correlation of the contextual variables with fair and poor SRH

\begin{tabular}{|c|c|c|c|c|c|c|c|}
\hline & $\begin{array}{l}\text { Fair and } \\
\text { poor SRH }\end{array}$ & $\begin{array}{l}\text { Voter } \\
\text { turnout }\end{array}$ & $\begin{array}{c}\text { Political } \\
\text { activity }\end{array}$ & $\begin{array}{c}\text { Social } \\
\text { participation }\end{array}$ & $\begin{array}{l}\text { Gross national } \\
\text { income per capita }\end{array}$ & $\begin{array}{l}\text { Total health } \\
\text { expenditure }\end{array}$ & $\begin{array}{l}\text { Freedom } \\
\text { index }\end{array}$ \\
\hline Voter turnout & 0.005 & & & & & & \\
\hline Political activity ${ }^{1}$ & $-0.447^{* * *}$ & $0.320^{* * *}$ & & & & & \\
\hline Social participation ${ }^{1}$ & $-0.573^{* * *}$ & $0.348^{* * *}$ & $0.426^{* * *}$ & & & & \\
\hline Gross national income per capita & $-0.394^{* * *}$ & $0.203^{* * *}$ & $0.796^{* * *}$ & $0.169^{* * *}$ & & & \\
\hline Total health expenditure $(\%)^{2}$ & $-0.216^{* * *}$ & $0.104^{* * *}$ & $0.686^{* * *}$ & $0.115^{* * *}$ & $0.701^{* * *}$ & & \\
\hline Freedom index ${ }^{3}$ & $0.438^{* * *}$ & $-0.460^{* * *}$ & $-0.661^{* * *}$ & $-0.366^{* * *}$ & $-0.625^{* * *}$ & $-0.539 * * *$ & \\
\hline Public health expenditure $(\%)^{2}$ & -0.001 & $0.240^{* * *}$ & $0.420^{* * *}$ & $0.091^{* * *}$ & $0.403^{* * *}$ & $0.241^{* * *}$ & $-0.420 * * *$ \\
\hline
\end{tabular}

$\mathrm{SRH}$, self-rated health.

${ }^{1}$ For political activity and social participation, a higher score indicates a higher participation.

${ }^{2}$ The total health expenditure (\%) and public health expenditure (\%) represents the percentage of spending on the gross national income.

${ }^{3}$ For the freedom index, a higher score indicates a lower degree of freedom.

${ }^{* * *} p<0.0001$. 
Table 3. Regression coefficients from the multi-level logistic regression among those with fair and poor self-rated health, 44 countries

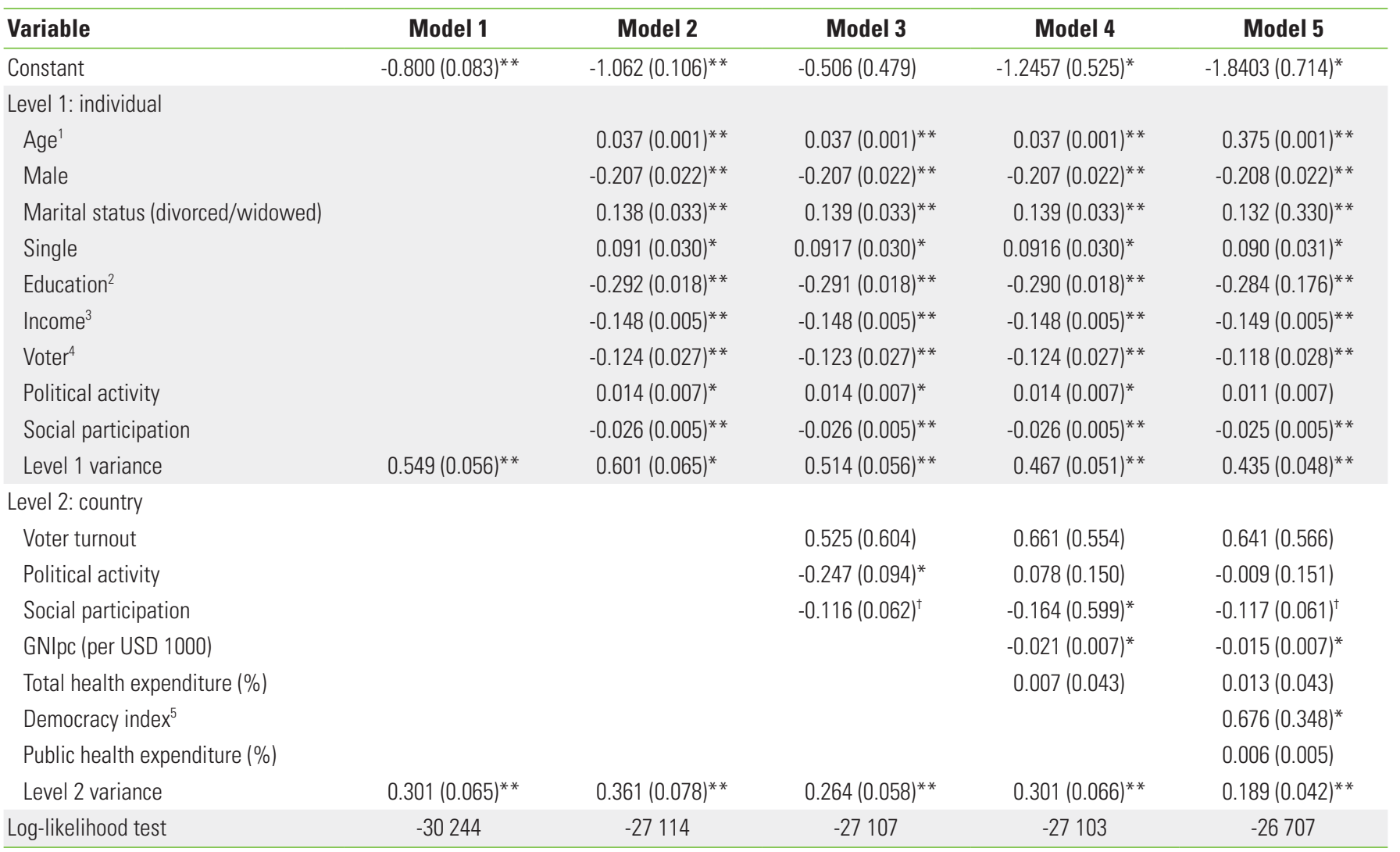

GNIpc, gross national income per capita; USD, United States dollar.

${ }^{1}$ Age as a continuous variable.

Education was classified into three categories.

${ }^{3}$ Income was classified into four categories

${ }^{4}$ Voters consisted of those who had participated in voting.

${ }^{5}$ The higher the democracy index, the lower the freedom.

${ }^{\dagger} p<0.10,{ }^{*} p<0.05,{ }^{* *} p<0.001$

ger associated with $\mathrm{SRH}$.

The contextual level variables had some distinguishing features in the subset analysis. According to model 3, countries with high social participation and political activity reported good SRH. However, when we added the GNIpc and total health expenditure to the analysis, civic participation lost its effect. Among the OECD countries, the GNIpc and total health expenditure were not significantly associated with the subjective health of the state.

In the final model, model 5, the democracy index, public health expenditure, economic status, and political activity were statistically significant variables. Countries with high unconventional political participation and public health expenditure, mature democracies, and good economic statuses reported good SRH. The effect of political activity disappeared in model 4 , but reappeared in model 5 . In the analysis on the entire group of 44 countries, social participation was a more robust variable; however, among the OECD countries, unconventional political activity was the more robust variable in the subset analysis.

\section{DISCUSSION}

This study explored the effect of civic participation on health by utilizing the multi-level modeling of cross-national data. At the individual level, people who participated in voting and voluntary social associations tended to report better SRH than those who did not participate in these organizations did, after controlling for demographic and socioeconomic variables. This result is similar to those of previous studies, which have 
Table 4. Regression coefficients from the multi-level logistic regression among those with fair and poor self-rated health, 18 OECD countries

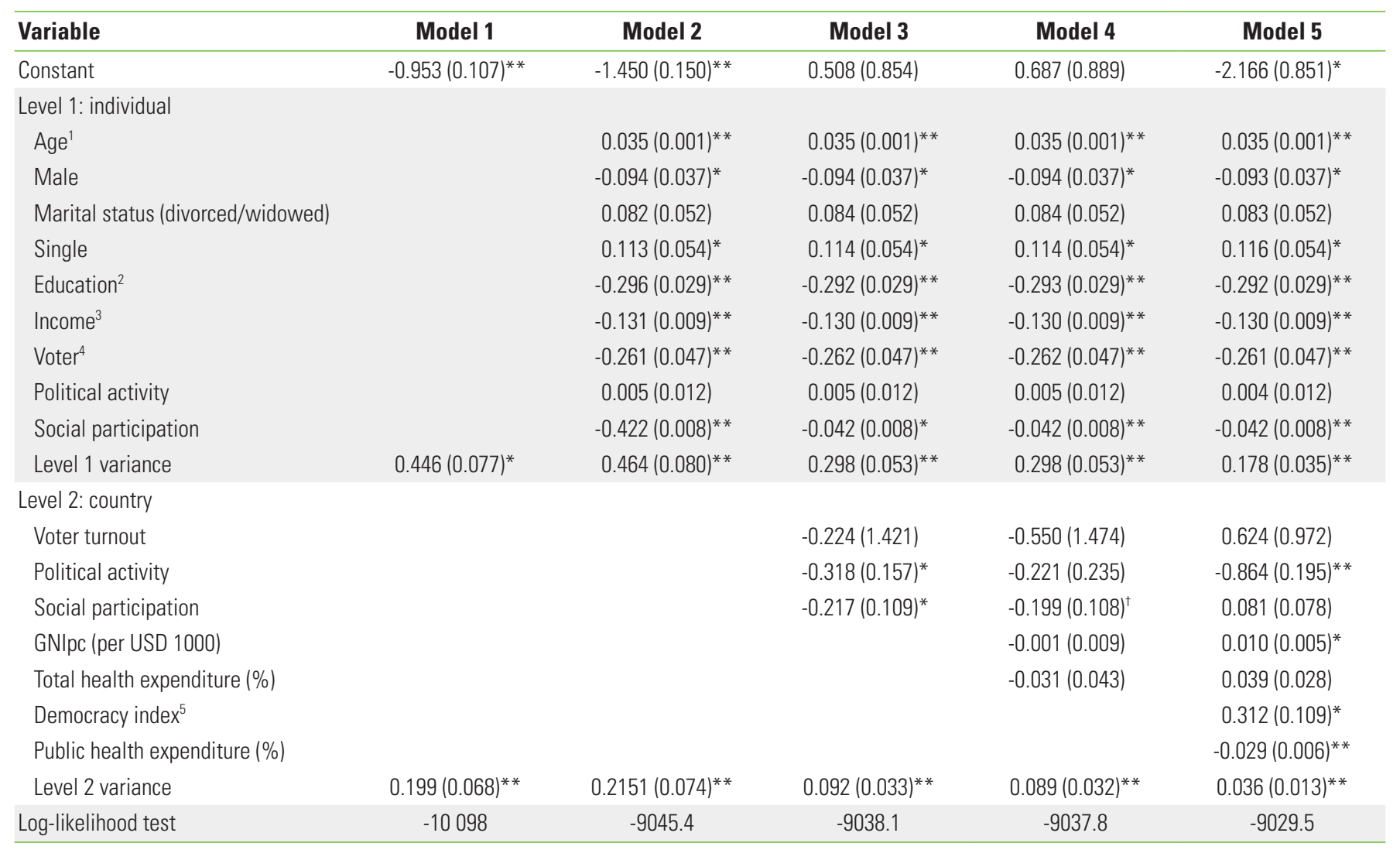

OECD, Organization for Economic Cooperation and Development; GNIpc, gross national income per capita; USD, United States dollar.

${ }^{1}$ Age as a continuous variable.

Education was classified into three categories.

${ }^{3}$ Income was classified into four categories.

${ }^{4}$ Voters consisted of those who had participated in voting.

${ }^{5}$ The higher the democracy index, the lower the freedom.

${ }^{\dagger} p<0.10,{ }^{*} p<0.05,{ }^{* *} p<0.001$

explored the positive association between social participation and voting with better subjective health status [34-38].

Previous studies have also reported a negative association between political activity and poor SRH as was revealed in our analysis of 44 countries. The US Community Study and England Citizenship Survey used a multi-level model, and also had similar results $[13,34]$. One possible explanation for this negative association might be because participation in unconventional political activities typically might require the use of some personal resources. Having to put effort toward organizing a political activity and resisting an existing power structure might negatively influence one's own productivity and/or personal relationships, which may in turn lead to a poor subjective health status [34]. However, this negative effect of political activity on the individual level disappeared in model 5 . This at- tenuation might be because when the democratic status of a country and the amount of public spending for health is generally equal, individual political activity may not harm one's own subjective health status.

In addition, the negative association of political activity with poor SRH became statistically insignificant in the subset analysis of the OECD countries. This result may reflect the idea that developed countries with mature democracies might have decreased personal burden among those who are politically active, and even encourage individual engagement in civic life.

The contextual effects of sociopolitical participation on SRH were also found. In the analysis of the 44 countries, political activity and social participation were significantly associated with good SRH before adjusting for the wealth of the country. However, after including the country's wealth, the percentage 
of the total health expenditure, the democracy index, and the percentage of public health expenditure, the GNIpc and democracy index were the only significant factors $(p=0.05)$. The contextual effect of political activity was observed in model 3 only. If the results for social participation are interpreted using a relaxed criterion of $p<0.10$ indicating significance, then social participation was significant in models 3 to 5 .

We may argue that engagement in civic activities has a somewhat positive correlation with health according to our analysis. This result may confirm those of previous studies that investigated participation, which was mostly framed as social capital. In this way, we expect that an active civic society with shared values, norms, and reciprocity would help residents of that society achieve common goals, and this collective effort should lead to a generally good health status among these individuals [11]. In addition, there is evidence that confirms the correlation between social capital (measured as social support and trust) and socioeconomic inequalities in health. This evidence suggests that social capital might buffer and be dependent upon the socioeconomic inequalities in health, and this mechanism may likely apply to the association of direct civic participation and health status found in the present study [39].

In the subset analysis of the OECD countries, the GNIpc was not a significant factor in model 4 , but became a significant factor in model 5 . One interpretation of this finding might be that among developed countries, economic wealth can be translated into better health statuses if the level of democracy and public health expenditures are controlled and kept almost equal.

One novel feature of our study is that we added non-conventional political participation as a determinant of health. The positive effect of political activity on health was found significant in several models, mostly those performed in the subset analysis of the OECD countries. In general, social participation was the main significant factor determining SRH in the analysis of the 44 countries, and unconventional political participation was the main significant factor in the analysis of the OECD countries.

The democracy index was significantly associated with SRH in both analyses, but the percentage of public health expenditure was significant in only the subset analysis. Therefore, the SRH status of a country might initially depend on their level of material wealth and freedom, but after a certain degree of economic development, public health spending and political participation seems to be a more important determinant than material wealth and freedom are.
This study has several limitations. First, this study cannot determine a causal relationship because of its cross-sectional design. Second, our results might be subject to reverse causality, especially on an individual level. To overcome this limitation, longitudinal data and/or intermediate variables should be considered in future studies. Third, our dependent variable was a subjective measure of health. We tried to distinguish between compositional and contextual effects, so we employed the WVS, which includes an individual measure for civic participation, but the only available measure for health status in the data was SRH. Nevertheless, SRH is widely used as predictor of health and morality. Many other studies have explored the broader spectrum of social determinants of health by using SRH status as a generic measure of health $[34,38,40]$. Fourth we had hoped to utilize several country-level determinants of health that might deter the health status of the country such as the level of social trust [18,19], income inequality [17], type of health care system, and welfare regime [16,17], but these variables were not included in our analysis. Despite this limitation, we believe a strength of our study is that we compared civic participation with generally accepted monetary measures associated with health. In addition, unconventional political activities such as civic participation was analyzed.

In conclusion, civic participation may be associated with SRH status at both the individual and country levels. However, future prospective studies should explore the underlying pathways, mechanisms, and associations between civic participation and health.

\section{CONFLICT OF INTEREST}

The authors have no conflicts of interest with the material presented in this paper.

\section{REFERENCES}

1. Wallace C, Pichler F. More participation, happier society? A comparative study of civil society and the quality of life. Soc Indic Res 2009;93(2):255-274.

2. Besley T, Kudamatsu M. Health and democracy. Am Econ Rev 2006;96(2):313-318

3. Ross M. Is democracy good for the poor? Am J Pol Sci 2006; 50(4):860-874.

4. Ruger JP. Democracy and health. QJM 2005;98(4):299-304.

5. Putnam RD, Leonardi R, Nanetti R. Making democracy work: 
civic traditions in modern Italy. Princeton: Princeton University Press; 1994, p. 167.

6. Poortinga W. Social capital: an individual or collective resource for health? Soc Sci Med 2006;62(2):292-302.

7. Mansyur C, Amick BC, Harrist RB, Franzini L. Social capital, income inequality, and self-rated health in 45 countries. Soc Sci Med 2008;66(1):43-56.

8. Muntaner C, Lynch J, Smith GD. Social capital and the third way in public health. Crit Public Health 2000;10(2):107-124.

9. Navarro V. Special report on the political and social contexts of health: part I. Introduction: objectives and purposes of the study. Int J Health Serv 2003;33(3):407-417.

10. Navarro V, Borrell C, Benach J, Muntaner C, Quiroga A, Rodriguez-Sanz M, et al. The importance of the political and the social in explaining mortality differentials among the countries of the OECD, 1950-1998. Int J Health Serv 2003;33(3):419-494.

11. Szreter $S$, Woolcock M. Health by association? Social capital, social theory, and the political economy of public health. Int J Epidemiol 2004;33(4):650-667.

12. Woolcock M. Social capital and economic development: toward a theoretical synthesis and policy framework. Theory Soc 1998;27(2):151-208.

13. Poortinga W. Community resilience and health: the role of bonding, bridging, and linking aspects of social capital. Health Place 2012;18(2):286-295.

14. Lofors J, Sundquist K. Low-linking social capital as a predictor of mental disorders: a cohort study of 4.5 million Swedes. Soc Sci Med 2007;64(1):21-34.

15. Sundquist J, Johansson SE, Yang M, Sundquist K. Low linking social capital as a predictor of coronary heart disease in Sweden: a cohort study of 2.8 million people. Soc Sci Med 2006; 62(4):954-963.

16. Chung $\mathrm{H}$, Muntaner C. Political and welfare state determinants of infant and child health indicators: an analysis of wealthy countries. Soc Sci Med 2006;63(3):829-842.

17. Muntaner C, Lynch JW, Hillemeier M, Lee JH, David R, Benach J, et al. Economic inequality, working-class power, social capital, and cause-specific mortality in wealthy countries. Int J Health Serv 2002;32(4):629-656.

18. Jen MH, Sund ER, Johnston R, Jones K. Trustful societies, trustful individuals, and health: an analysis of self-rated health and social trust using the World Value Survey. Health Place 2010; 16(5):1022-1029.

19. Kim D, Baum CF, Ganz ML, Subramanian SV, Kawachi I. The contextual effects of social capital on health: a cross-national instrumental variable analysis. Soc Sci Med 2011;73(12):16891697.

20. World Value Survey Group. World Value Survey Wave 5 (20052008) official aggregate [cited 2013 Dec 30]. Available from: http://www.worldvaluessurvey.org/WVSDocumentationWV5.jsp.

21. World Bank. World Bank national accounts data, and OECD National Accounts data files database; 2005 [cited 2013 Dec 30]. Available from: http://data.worldbank.org/indicator/ NY.GNP.PCAP.KD.

22. World Health Organization. Global health expenditure database; 2005 [cited 2013 Dec 30]. Available from: http://apps. who.int/nha/database/Home/Index/en.

23. Freedom House. Freedom in the world; 2005 [cited 2013 Dec 30]. Available from: https://freedomhouse.org/report-types/ freedom-world.

24. Idler EL, Benyamini Y. Self-rated health and mortality: a review of twenty-seven community studies. J Health Soc Behav 1997;38(1):21-37.

25. Quesnel-Vallee A. Self-rated health: caught in the crossfire of the quest for 'true' health? Int J Epidemiol 2007;36(6):11611164.

26. Filmer D, Pritchett $L$. The impact of public spending on health: does money matter? Soc Sci Med 1999;49(10):1309-1323.

27. Hitiris T, Posnett J. The determinants and effects of health expenditure in developed countries. J Health Econ 1992;11(2): 173-181.

28. Reinhardt UE, Hussey PS, Anderson GF. Cross-national comparisons of health systems using OECD data, 1999. Health Aff (Millwood) 2002;21(3):169-181.

29. Nixon J, Ulmann P. The relationship between health care expenditure and health outcomes. Evidence and caveats for a causal link. Eur J Health Econ 2006;7(1):7-18.

30. Granlund D. The effect of health care expenditure on sickness absence. Eur J Health Econ 2010;11(6):555-568.

31. Franco A, Alvarez-Dardet C, Ruiz MT. Effect of democracy on health: ecological study. BMJ 2004;329(7480):1421-1423.

32. Mackintosh M, Koivusalo M. Commercialization of health care: global and local dynamics and policy responses. Basingstoke: Palgrave Macmillan; 2005, p. 14-18.

33. Houweling TA, Caspar AE, Looman WN, Mackenbach JP. Determinants of under- 5 mortality among the poor and the rich: a cross-national analysis of 43 developing countries. Int J Epidemiol 2005;34(6):1257-1265.

34. Kim D, Kawachi I. A multilevel analysis of key forms of commu- 
nity- and individual-level social capital as predictors of selfrated health in the United States. J Urban Health 2006;83(5): 813-826.

35. Rose R. How much does social capital add to individual health? A survey study of Russians. Soc Sci Med 2000;51(9): 1421-1435.

36. Kim SH. An individual-level study on the components of social capital and their relationships. Korean Polit Sci Rev 2008; 42(2):67-88.

37. Veenstra G. Social capital, SES and health: an individual-level analysis. Soc Sci Med 2000;50(5):619-629.
38. Song YL, Nam EW. The influence of social capital and health behaviors on self-rated health in South Korea. J Korean Soc Health Educ Promot 2009;26(3):1-13.

39. Uphoff EP, Pickett KE, Cabieses B, Small N, Wright J. A systematic review of the relationships between social capital and socioeconomic inequalities in health: a contribution to understanding the psychosocial pathway of health inequalities. Int J Equity Health 2013;12:54.

40. Blakely TA, Kennedy BP, Kawachi I. Socioeconomic inequality in voting participation and self-rated health. Am J Public Health 2001;91(1):99-104. 